\title{
AN ASSESSMENT OF UNSTIMULATED SALIVARY FLOW RATE, IgA AND CLINICAL ORAL DRYNESS AMONG ACTIVE AND PASSIVE SMOKERS
}

\author{
SEEME NIGAR ${ }^{1}$, SOBIA HASSAN ${ }^{2}$, AFSHEEN MAQSOOD ${ }^{3}$, NASEER AHMED ${ }^{4}$, MANSOUR AL-ASKAR $^{5}$, \\ SAMEER A. MOKEEM ${ }^{5}$, MONTASER N. ALQUTUB ${ }^{5}$, NADA ALDAHIAN ${ }^{6}$, EMAN I. ALSAGOB ${ }^{7}$, \\ ABDULRAHMAN A. ALMUBARAK ${ }^{5}$, FAHIM VOHRA ${ }^{8}$, and TARIQ ABDULJABBAR ${ }^{8}$ \\ ${ }^{1}$ Altamash Institute of Dental Medicine, Karachi, Pakistan \\ Department of Oral Pathology \\ ${ }^{2}$ Altamash Institute of Dental Medicine, Karachi, Pakistan \\ Department of Pathology \\ ${ }^{3}$ Bahria University Medical and Dental College, Karachi, Pakistan \\ Department of Oral Pathology \\ ${ }^{4}$ Altamash Institute of Dental Medicine, Karachi, Pakistan \\ Department of Prosthodontics \\ ${ }^{5}$ King Saud University, Riyadh, Saudi Arabia \\ Department of Periodontics and Community Dentistry, College of Dentistry \\ ${ }^{6}$ King Saud University, Riyadh, Saudi Arabia \\ Department of Restorative Dental Science, College of Dentistry \\ ${ }^{7}$ Princess Nourah bint Abdulrahman University, Riyadh, Saudi Arabia \\ Preventive Dental Sciences Department, Community Dentistry Division, College of Dentistry \\ ${ }^{8}$ King Saud University, Riyadh, Saudi Arabia \\ Department of Prosthetic Dental Science, College of Dentistry
}

\begin{abstract}
Objectives: The aim of this study was to assess the impact of smoking on the whole salivary flow rate (SFR), IgA levels and clinical oral dryness (COD) among active and passive smokers. Material and Methods: The participants were categorized as active smokers $(\mathrm{N}=54)$ or passive smokers $(\mathrm{N}=163)$. Saliva was collected in tubes and placed in ice storage at $-70^{\circ} \mathrm{C}$. Salivary IgA levels were assessed in duplication using the enzyme linked immunosorbent assay (ELISA) method. Following the saliva sample collection, the subjects were assessed for COD using the COD score, SFR and caries. Chi-square test, the t-test and ANOVA were employed to compare the clinical impact of the smoking status associated with specific variables (smoking status, number of cigarettes, active caries, gender, age, COD score, IgA level and SFR). A p-value of $<0.05$ was considered significant. Results: Two hundred and seventeen subjects with the mean age of $32.86 \pm 6.30$ years, with 145 males (66.8\%) and 72 females (33.2\%), were included in the study. Among the active smokers, $88.8 \%$ were males compared to $11.2 \%$ females. The active smokers had the mean age of 32.52 years,
\end{abstract}

Funding: this research was supported by the Deputyship for Research and Innovation, Ministry of Education in Saudi Arabia (project No. IFKSURG-1438-075). Received: January 25, 2021. Accepted: May 5, 2021.

Corresponding author: Tariq Abduljabbar, King Saud University, Department of Prosthetic Dental Science, College of Dentistry, Riyadh 11545, Saudi Arabia (e-mail: tajabbar@ksu.edu.sa). 
a COD score of 1.43, an IgA level of $1.39 \mathrm{~g} / \mathrm{l}$, and a SFR of $0.37 \mathrm{ml} / \mathrm{min}$. Among the passive smokers, $59.5 \%$ were males and $40.5 \%$ were females, with the mean age of 32.97 years, a COD score of $0.87 \mathrm{~g} / \mathrm{l}$, an IgA level of 1.47 , and a SFR of $0.42 \mathrm{ml} / \mathrm{min}$. Active caries showed a positive correlation with the number of cigarettes, with significance in the $>35$ years age group $(p<0.05)$. Conclusions: The study demonstrated significant differences in SFR, IgA and COD scores among the active and passive smokers. The number of cigarettes had a negative impact on saliva production, IgA levels, the oral health status, and the progression of caries with respect to age and gender. Smoking potentially leads to xerostomia associated with active caries. Int J Occup Med Environ Health. 2022;35(1):39-51

Key words:

IgA, xerostomia, passive smokers, active smokers, salivary flow rate, oral dryness

\section{INTRODUCTION}

Smoking tobacco is a public health hazard that affects nearly 1 billion people worldwide [1]. It is established that cigarette smoking is one of the critical risk factors for triggering oral disorders. Smokers are exposed to more than 7000 chemicals in a puff, which alters the salivary component, resulting in impaired oral protection [2]. Many clinical and epidemiological studies revealed that passive smokers (i.e., people who are exposed to environmental smoke) presented with detrimental oral health alterations comparable to those observed in active smokers $[1,2]$. The harmful substances contained in cigarettes create health risks for both groups equally; however, the risk remains higher for active smokers compared to passive smokers, due to direct deposits and breakdown of toxic substances in the blood.

Saliva provides an innate defense system, which continuously baths the oral tissue. The presence of saliva is essential to promote the remineralization of teeth against caries and to continuously wash debris to disturb the pathogenic bacterial activity [3]. The salivary flow rate (SFR) plays an important role in facilitating oral haemostasis and protects oral mucosa against dryness [4]. Currently, $46 \%$ of the population has reported the subjective feeling of dry mouth [5]. Moreover, flow reduction or dryness compromise oral health, resulting in some associated problems such as caries, calculus, distraught speech and swallowing difficulty (dysphagia). The normal SFR ranges $0.3-0.65 \mathrm{ml} / \mathrm{min}$ to $1.5-6 \mathrm{ml} / \mathrm{min}$ under stimulation; thus a SFR of $<0.2 \mathrm{ml} / \mathrm{min}$ is suggestive of hyposalivation due to some external and internal factors such as smoking and the hypofunction of glands $[4,6]$.

In addition, IgA is a major component of saliva, which protects the oral cavity. It has been reported that active smoking alters the protective components such as IgA in saliva, thereby decreasing its resistance to oral pathogens and upsurging periodontal structure destruction $[7,8]$. Currently, a new tool is designed to facilitate an assessment of oral dryness alongside SFR measurement [9]. The clinical oral dryness (COD) score is an effective instrument to determine hyposalivation and reduced oral mucosal wetness, indicating a physiological basis for the feeling of dryness [10]. Thus, studies have marked the COD score as an authentic tool for measuring the severity of hyposalivation $[9,10]$.

It has been found that new smokers often report increased salivary flow due to constant stimulation by nicotine but with reduced oral protective constituents. However, some prospective studies have suggested that chronic smoking damages secretory cells, which results in lowered SFR [11,12]. Interestingly, a similar outcome has been observed in passive smokers indicating that the presence of nicotine is a potent trigger. Nonetheless, the effect of smoking is controversial as studies have shown weak to no correlation between oral dryness and SFR $[13,14]$. It is hypothesized that passive smokers will show a similar influence on the unstimulated whole SFR, IgA levels and COD as those reported by active smokers. Thus, to explore the effect of smoking, the present study aimed to assess the impact of smoking habits on the unstimulated whole SFR, IgA levels and COD among active and passive smokers. 


\section{MATERIAL AND METHODS}

\section{Ethical consideration}

The study was conducted as per the ethical standards of the Helsinki declaration (modified in 2003) and approved by the institutional review board in AIDM/EC/01/ 2019/03. All participants completed an informed consent form regarding their voluntary participation and had the right to withdraw from the study without any consequences.

\section{Study design and participants}

A cross-sectional study was conducted in the outpatient department of the Altamash Institute of Dental Medicine, Karachi, Pakistan, in the period of June-December 2019. The study enrolled a total of 217 patients from the outpatient department. The participants were categorized into 2 groups based on their smoking habits, i.e., active vs. passive smokers.

\section{Inclusion and exclusion criteria}

Active smokers were individuals smoking 10 cigarettes/day in the past 12 months $[15,16]$ and passive smokers were those who did not smoke tobacco but were exposed to secondhand smoke or environmental tobacco smoke every day, via their smoking friends, family or colleagues in the past 12 months. Any participant with a pre-existing medical condition, severe head or neck injury, xerostomia, undergoing radiotherapy, wearing dentures and suffering from chronic infections were excluded from the study to avoid interference with the outcome. In addition, individuals taking medication, such as $\beta$-blockers, steroids, anti-psychotics, anti-depressants and oral contraceptives were also excluded (due to interference with SFR).

\section{Questionnaire}

An oral examination was performed for all subjects. The questionnaire administered by a dental surgeon included questions regarding the patient's demographics (age, gender, and educational status), smoking (number of cigarettes, type of smoker, duration and frequency of smoking) and the self-perceived oral health status (sensation of unlikable taste or halitosis, saliva production, oral dryness, swallowing, caries, oral lesions and other associated symptoms). The questionnaire was administered following the saliva sample collection.

\section{Unstimulated whole SFR assessment}

The saliva sample collection procedure was conducted between 8:00 a.m. and 12:00 p.m. to reduce the fluctuations associated with the circadian rhythm of salivary secretion. After getting the consent from the participants, the unstimulated whole saliva was collected in a standardized manner. Each participant was instructed to avoid eating, drinking, smoking and any oral hygiene process for $60 \mathrm{~min}$ prior to and during the saliva sampling collection procedure. Subsequently, each subject's oral health status was assessed and the presence of a number of unrestored active caries on the tooth surface was noted.

Saliva was collected by 2 operators, and each patient was seated in a dental chair in an upright position with his/her head prone forward in order to collect the saliva from the floor of the mouth. The patients were instructed to minimize lips and tongue movement and to refrain from swallowing during the saliva sample collection. The patients were further instructed to accumulate saliva in the mouth for $5 \mathrm{~min}$ (unstimulated) and expectorate into a graduated measuring cylinder through a funnel. The patient's SFR was measured in $\mathrm{ml} / \mathrm{min}$. The saliva samples were immediately stored in disposable centrifuge tubes and placed in ice. The samples were then aliquoted, stored at $-70^{\circ} \mathrm{C}$ and used within 6 months.

\section{Assessment of CODs}

Following the saliva sample collection, the subjects were assessed for the level of oral dryness. The patients were ranked on a scale of $10 \mathrm{pts}$, each level being a dryness at- 
Table 1. General characteristics of the study groups (active and passive smokers) from the outpatient department of the Altamash Institute of Dental Medicine, Karachi, Pakistan, June-December 2019

\begin{tabular}{|c|c|c|c|}
\hline \multirow{2}{*}{ Variable } & \multicolumn{3}{|c|}{$\begin{array}{l}\text { Participants } \\
(\mathrm{N}=217)\end{array}$} \\
\hline & $\begin{array}{l}\text { active smokers } \\
\quad(\mathrm{N}=54)\end{array}$ & $\begin{array}{c}\text { passive smokers } \\
\quad(\mathrm{N}=163)\end{array}$ & total \\
\hline Age [years] (M $\pm S D)$ & $32.52 \pm 5.87$ & $32.97 \pm 6.45$ & $32.86 \pm 6.304$ \\
\hline \multicolumn{4}{|l|}{ Gender [n (\%)] } \\
\hline male & $48(88.88)$ & $97(59.50)$ & $145(66.8)$ \\
\hline female & $6(11.11)$ & $66(30.41)$ & $72(33.2)$ \\
\hline Cigarettes [n] (M $\pm S D)$ & $5.09 \pm 2.421$ & - & $5.09 \pm 2.421$ \\
\hline
\end{tabular}

tribute in the mouth. Each characteristic observed was scored as $1 \mathrm{pt}$ and the total score indicated the level of severity (Appendices 1 and 2).

\section{Measurement of IgA}

Salivary IgA levels were assessed in duplication using the enzyme linked immunosorbent assay (ELISA) method. The testing was performed at the department of pathology of the Institute of Dental Medicine for the assay. The centrifugation of the samples was done for $15 \mathrm{~min}$ at $12000 \mathrm{~g}$ and $4^{\circ} \mathrm{C}$ to settle the salivary debris and mucin. To measure the IgA levels, the instructions by Bethyllaboratories Inc. (Montgomery, TX, USA), catalog No. E80-102, were followed for standardized analysis. The standard ELISA method was adopted from the authors' previous study [17]. The concentration of IgA was measured in $\mathrm{g} / \mathrm{l}$.

\section{Statistical analysis}

Data were analyzed using the statistical software for social sciences (SPSS v. 22, Chicago, IL, USA). The quantitative analysis was reported as mean $(\mathrm{M}) \pm$ standard deviation (SD). The variables assessed included age, the number of cigarettes, COD, the IgA level and SFR. Descriptive analysis was reported as frequencies and percentages of variables including gender, smoking and carious lesions.
An independent t-test and $\chi^{2}$ test were used to compare SFR, COD and IgA levels, as well as active caries among the active vs. passive smokers. Confounding variables such as age and gender were addressed through stratification. Post-stratification ANOVA was employed to measure the clinical impact of the smoking status associated with enlisted variables (smoking status, number of cigarettes, active caries, gender, age, CODS, IgA level and SFR). A pvalue of $<0.05$ was considered significant.

\section{RESULTS}

\section{Patient characteristics in the study}

The study included 217 subjects with the mean age of $32.86 \pm 6.30$ years (a range of $22-55$ years) (Table 1), of whom 145 were males (66.8\%) and 72 were females (33.2\%). The patients were classified based on their smoking status; 163 were passive smokers $(75.1 \%)$ whereas 54 were active smokers (24.9\%) with 5.09 average cigarettes per day (a range of 1-11) (Table 1). Among these patients, 45.6\% $(\mathrm{N}=99)$ had 1 unrestored caries and $32.3 \%(\mathrm{~N}=70)$ showed $\geq 2$ unrestored caries. However, $22.1 \%(\mathrm{~N}=48)$ of the patients were caries free.

The oral health status was evaluated and scored according to COD with a mean ranging $0-4$. This was followed by the salivary assessment, which revealed the following average values of IgA, SFR and COD: M \pm SD $1.45 \pm 0.15 \mathrm{~g} / \mathrm{l}$, 
Table 2. Comparison of salivary flow rate (SFR), IgA levels and clinical oral dryness (COD) scores between active and passive smokers from the outpatient department of the Altamash Institute of Dental Medicine, Karachi, Pakistan, June 2019

\begin{tabular}{|c|c|c|c|}
\hline \multirow{2}{*}{ Variable } & \multicolumn{2}{|c|}{$\begin{array}{l}\text { Participants } \\
(\mathrm{N}=217)\end{array}$} & \multirow{2}{*}{$p^{*}$} \\
\hline & $\begin{array}{l}\text { active smokers } \\
\quad(\mathrm{N}=54)\end{array}$ & $\begin{array}{l}\text { passive smokers } \\
\quad(\mathrm{N}=163)\end{array}$ & \\
\hline SFR [ml/min] (M \pm SD) & $0.374 \pm 0.13$ & $0.429 \pm 0.08$ & 0.001 \\
\hline $\lg A[g / l](M \pm S D)$ & $1.392 \pm 0.17$ & $1.470 \pm 0.13$ & 0.001 \\
\hline COD score $(M \pm S D)$ & $1.43 \pm 1.22$ & $0.87 \pm 1.05$ & 0.001 \\
\hline
\end{tabular}

* In the t-test, $\mathrm{p}<0.05$ displays a significant difference between the 2 study groups.

$\mathrm{M} \pm \mathrm{SD} 0.416 \pm 0.11 \mathrm{ml} / \mathrm{min}$ and $\mathrm{M} \pm \mathrm{SD} 1.25 \pm 1.13$, respectively (Table 2 and Figure 1).

\section{Assessment of active vs. passive smokers}

Among the active smokers, $88.8 \%(\mathrm{~N}=48)$ were males compared to $11.2 \%$ females $(\mathrm{N}=6)$. The active smokers had the mean age of 32.52 years, a COD score of 1.43 , an IgA level of $1.39 \mathrm{~g} / \mathrm{l}$, and a SFR of $0.37 \mathrm{ml} / \mathrm{min}$ (Table 2 and Figure 1). Among the active smokers, the majority had $\geq 1$ unrestored caries ( $\mathrm{N}=21,38.9 \%)$, followed by $\geq 2$ unrestored caries $(\mathrm{N}=27)$, and only $6(11.1 \%)$ subjects were caries free.

Among the passive smokers, $59.5 \%(\mathrm{~N}=97)$ were males and $40.5 \%(\mathrm{~N}=66)$ were females, with the mean age of 32.97 years, a COD score of 0.87 , an IgA level of $1.47 \mathrm{~g} / \mathrm{l}$, and a SFR of $0.42 \mathrm{ml} / \mathrm{min}$. Among the passive smokers, the majority had $\geq 1$ unrestored caries ( $\mathrm{N}=78,47.9 \%$ ), 43 patients had $\geq 2$ unrestored surfaces, and 42 participants had no caries (25.8\%).

\section{Impact of associated variables on the oral health status}

With respect to age, a significant difference was observed between the active and passive smokers. As regards the IgA levels, SFR and COD, the majority of the participants were aged $\leq 35$ years $(\mathrm{N}=200)$ with only 17 subjects in the $>35$ years age group. Nevertheless, both age categories

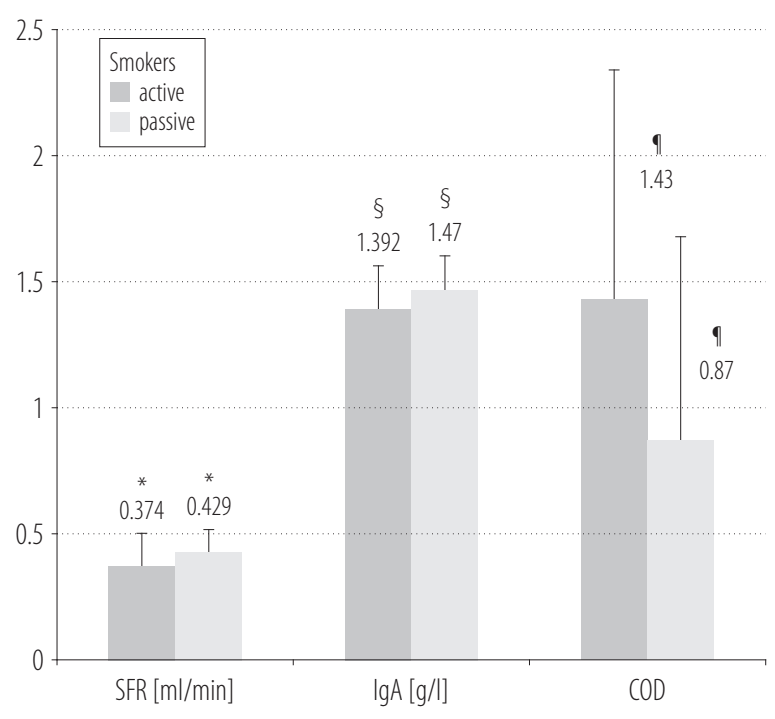

Similar symbols show significant differences in the corresponding groups.

Figure 1. Comparison of salivary flow rate (SFR), IgA levels and clinical oral dryness (COD) scores among active and passive smokers in the outpatient department of the Altamash Institute of Dental Medicine, Karachi, Pakistan, in June-December 2019

( $>35$ and $\leq 35$ years) showed a significant difference $(\mathrm{p}<0.05)$ (Table 3). The passive smokers displayed a higher mean value of IgA in the $<35$ years age group $(\mathrm{M} \pm \mathrm{SD} 1.48 \pm 0.13)$ whereas the lowest value was reported in the active smokers in the $>35$ years age group $(\mathrm{M} \pm \mathrm{SD} 1.08 \pm 0.17)$. Likewise, for SFR, a higher mean value was observed among the passive smokers aged $<35$ years $(\mathrm{M} \pm \mathrm{SD} 0.43 \pm 0.09)$ compared to the active smokers $(\mathrm{M} \pm \mathrm{SD} 0.38 \pm 0.14)$, 
Table 3. Comparison between active and passive smokers in terms of age in the outpatient department of the Altamash Institute of Dental Medicine, Karachi, Pakistan, June 2019

\begin{tabular}{|c|c|c|c|}
\hline \multirow{2}{*}{ Variable } & \multicolumn{2}{|c|}{$\begin{array}{l}\text { Participants } \\
(\mathrm{N}=217)\end{array}$} & \multirow{2}{*}{$p^{*}$} \\
\hline & $\begin{array}{l}\text { active smokers } \\
\quad(\mathrm{N}=54)\end{array}$ & $\begin{array}{l}\text { passive smokers } \\
\quad(\mathrm{N}=163)\end{array}$ & \\
\hline \multicolumn{4}{|l|}{ Age group } \\
\hline \multicolumn{4}{|l|}{$<35$ years } \\
\hline $\lg A$ & $1.42(0.15)$ & $1.48(0.13)$ & 0.001 \\
\hline SFR & $0.38(0.14)$ & $0.43(0.09)$ & 0.001 \\
\hline$C O D$ & $1.22(1.02)$ & $0.75(0.97)$ & 0.007 \\
\hline \multicolumn{4}{|l|}{$>35$ years } \\
\hline $\lg A$ & $1.08(0.17)$ & $1.41(0.08)$ & 0.012 \\
\hline SFR & $0.25(0.06)$ & $0.38(0.04)$ & 0.004 \\
\hline$C O D$ & 4 & $2.15(1.14)$ & 0.004 \\
\hline \multicolumn{4}{|l|}{ Gender } \\
\hline \multicolumn{4}{|l|}{ female } \\
\hline $\lg A$ & $1.5(0.06)$ & $1.55(0.03)$ & 0.001 \\
\hline SFR & $0.57(0.34)$ & $0.46(0.11)$ & 0.076 \\
\hline$C O D$ & $0.67(1.03)$ & $0.73(1.09)$ & 0.896 \\
\hline \multicolumn{4}{|l|}{ male } \\
\hline $\lg A$ & $1.38(0.18)$ & $1.42(0.15)$ & 0.204 \\
\hline SFR & $0.35(0.06)$ & $0.41(0.06)$ & 0.001 \\
\hline$C O D$ & $1.52(1.22)$ & $0.96(1.02)$ & 0.004 \\
\hline
\end{tabular}

COD - clinical oral dryness; SFR - salivary flow rate.

* In the t-test, $\mathrm{p}<0.05$ displays a significant difference between the 2 study groups.

whereas the lowest mean value of SFR was reported in the active smokers aged $>35$ years $(\mathrm{M} \pm \mathrm{SD} 0.25 \pm 0.06)$ (Table 3). Thus, the study reported that the mean IgA levels and SFR among the active smokers were lower as compared to the passive smokers, with the $>35$ years age group presenting a greater adverse influence.

With respect to gender, the highest mean value for IgA was observed in the female passive smokers $(\mathrm{M} \pm \mathrm{SD}$ $1.55 \pm 0.03)$, whereas the lowest one was observed in the male active smokers $(\mathrm{M} \pm \mathrm{SD} 1.38 \pm 0.18)$ (Table 3 ). Similarly, for SFR, the maximum mean value was obtained for the female active smokers $(\mathrm{M} \pm \mathrm{SD} 0.57 \pm 0.34)$ compared to the male active smokers $(\mathrm{M} \pm \mathrm{SD} 0.35 \pm 0.06)$ for whom it was the lowest. Thus, the study outcome reflected a lower IgA level among the active smokers compared to the passive smokers; however, a significant difference was only observed in the males compared to the females $(\mathrm{p}=0.01)$.

The COD scores among the active smokers were higher as compared to the passive smokers. The highest mean COD score was recorded in the male $(\mathrm{M} \pm \mathrm{SD} 1.52 \pm 1.22)$ in contrast to female active smokers, in the latter case displaying the lowest mean value $(\mathrm{M} \pm \mathrm{SD} 0.67 \pm 1.03)$. Likewise, the $>35$ years age group showed the highest 
Table 4. Comparison between active and passive smokers in terms of active caries, age and gender in the outpatient department of the Altamash Institute of Dental Medicine, Karachi, Pakistan, June 2019

\begin{tabular}{|c|c|c|c|c|c|c|c|}
\hline \multirow{2}{*}{ Variable } & \multirow{2}{*}{$\begin{array}{l}\text { Active caries } \\
\text { score }\end{array}$} & \multicolumn{2}{|c|}{$\begin{array}{c}\text { Participants } \\
(\mathrm{N}=217)\end{array}$} & \multirow{2}{*}{$p^{*}$} & \multicolumn{2}{|c|}{$\begin{array}{c}\text { Participants } \\
(N=72)\end{array}$} & \multirow{2}{*}{$p^{*}$} \\
\hline & & $\begin{array}{l}\text { active smokers } \\
\qquad(\mathrm{N}=200)\end{array}$ & $\begin{array}{l}\text { passive smokers } \\
\qquad(\mathrm{N}=17)\end{array}$ & & $\begin{array}{l}\text { active smokers } \\
\qquad(\mathrm{N}=6)\end{array}$ & $\begin{array}{l}\text { passive smokers } \\
\qquad(\mathrm{N}=66)\end{array}$ & \\
\hline \multicolumn{8}{|l|}{ Age } \\
\hline \multirow[t]{4}{*}{$<35$ years } & 0 & 6 & 41 & 0.052 & & & \\
\hline & 1 & 19 & 68 & & & & \\
\hline & 2 & 15 & 32 & & & & \\
\hline & 3 & 10 & 9 & & & & \\
\hline \multirow[t]{4}{*}{$>35$ years } & 0 & 0 & 1 & 0.004 & & & \\
\hline & 1 & 2 & 10 & & & & \\
\hline & 2 & 0 & 2 & & & & \\
\hline & 3 & 2 & 0 & & & & \\
\hline \multicolumn{8}{|l|}{ Gender } \\
\hline \multirow[t]{4}{*}{ females } & 0 & & & & 0 & 14 & 0.006 \\
\hline & 1 & & & & 5 & 49 & \\
\hline & 2 & & & & 1 & & \\
\hline & 3 & & & & 0 & 3 & \\
\hline \multirow[t]{4}{*}{ males } & 0 & 6 & 28 & & 6 & 28 & 0.004 \\
\hline & 1 & 16 & 29 & & 16 & 29 & \\
\hline & 2 & 14 & 34 & & 14 & 34 & \\
\hline & 3 & 12 & 6 & & 12 & 6 & \\
\hline
\end{tabular}

${ }^{*}$ In ANOVA, $p<0.05$ displays a significant difference between the 2 study groups.

mean COD scores $(4 \pm 0)$ whereas the lowest value was reported in the female passive smokers $(\mathrm{M} \pm \mathrm{SD} 2.15 \pm 1.14)$ (Table 3). A significant impact was noted in the males for COD scores $(\mathrm{p}=0.004)$. Thus, the outcome indicates a negative impact of smoking on saliva production and salivary protective function with the highest probability of occurrence in males (low COD and SFR outcomes) irrespective of age.

Furthermore, the relationship between the frequency of unrestored caries and the smoking status was statistically significant $(\mathrm{p}<0.05)$ with the majority of active caries observed among the passive smokers $(\mathrm{N}=121)$ compared to the active smokers $(\mathrm{N}=48)$ (Table 4). The out- come revealed that the majority of the active smokers who smoked $\leq 5$ cigarettes a day had $\geq 1$ unrestored caries $(\mathrm{N}=21)$. Both genders presented a significant difference between the active and passive smokers with the highest number of the latter with $\geq 1$ unrestored caries surface $(\mathrm{N}=68, \mathrm{p}=0.05)$. Active caries showed a positive correlation with the number of cigarettes, with higher significance in the $>35$ years age group $(\mathrm{p}<0.05)$.

It was observed that the IgA levels $(\mathrm{M} \pm \mathrm{SD} 1.46 \pm 0.09)$ and SFR $(M \pm S D 0.40 \pm 0.16)$ of the active smokers smoking $\leq 5$ cigarettes a day were greatly affected; however, the highest COD scores were observed only in those smokers who smoked $>5$ cigarettes a day $(\mathrm{M} \pm \mathrm{SD} 2.17 \pm 0.92)$ 
(Table 4). Nonetheless, cigarette smoking intensity only influenced the IgA levels and COD scores $(\mathrm{p}=0.01)$ to a significant extent, but not SFR $(p=0.08)$. This suggests that a long smoking history leads to the chronic condition of xerostomia associated with active caries progress.

\section{DISCUSSION}

This study was based on the hypothesis that passive smoking would show a similar influence on the unstimulated whole SFR, IgA levels and COD as that reported for active smoking. However, the outcome revealed that the difference in the smoking status has a significant impact on saliva production and its constituents $(\mathrm{p}=0.01)$. The active smokers showed higher COD scores with lower IgA levels and SFR compared to the passive smokers, irrespective of age. Moreover, the number of cigarettes smoked showed a significant influence on caries progression mainly in the active smokers representing older age groups. Thus, the smoking status was identified as the main factor for triggering oral health problems; however, age and gender played an important role as confounding factors. Therefore, the initial hypothesis was rejected.

The present study identified that the active smokers showed higher oral dryness due to low SFR and low oral protection (decreased IgA levels) compared to the passive smokers. According to Uneo et al. [18], tobacco smoke contains numerous detrimental constituents, such as oxidant and pro-oxidant compounds, which trigger free radical formation and contribute to oxidative stress. The effect of these deleterious constituents is not influenced by smoking habits; however, the negative impact is evidently present in the passive smokers due to exposure to the toxins in smoke. Studies have reported that prolonged smoking with toxin deposition destroys salivary cells, mainly those of the parotid glands $[11,19]$. Hence, saliva production is compensated by the submandibular and sublingual gland, which produces thick mucus saliva with low protective substances and acts as an agent for carcinogenesis [20].

Coinciding with previous studies [11,21], the present study has reported that, irrespective of the exact smoking habits, exposure to smoke is a critical factor in stimulating saliva production and influencing its constituents. The literature presents contradictory outcomes of nicotine stimulation among smokers. The presence of nicotine in tobacco smoke directly interacts with areas of the oral cavity, mainly those of the parotid glands, and therefore has an immediate effect on saliva production. Benedetti et al. [7] reported that SFR initially increased drastically under nicotine stimulation; however, with time it was reduced due to long-term exposure to nicotine and other toxic components that damage the salivary gland tissues in various patterns causing dry mouth. However, Petrusic et al. [11] explained that chronic smoking did not adversely affect the salivary reflex and salivation as nicotine and cytisine are often used as a sialogogue to treat xerostomia. Therefore, it is suggested that smoking alone cannot influence a long-term change in the saliva.

Similarly, the IgA levels were reported to be significantly lower in the active smokers compared to the passive smokers. Literature has reported that the constant presence of nicotine in blood levels alters the production of immunoglobulins, the innate defense line against the pathogens [22]. These toxic products change the T-cell immunoregulation and B-cell differentiation, which fortify the oral mucosa against periodontal pathogenic bacteria. Thus, active cigarette smokers generally present with a higher susceptibility of diminished immunoglobulin levels and decreased phagocytic activity of neutrophils, in contrast to passive smokers [20,23]. Moreover, a reduced level of immunoglobulins is known to directly correlate with periodontal inflammation, which was also observed in almost all of the smokers involved in the present study. Thus, the lack of proper oral hygiene maintenance and 
the number of cigarettes were identified as risk factors for periodontal disease among smokers.

Furthermore, the present study revealed that the majority of the passive smokers had $>1$ unrestored caries in contrast to the active smokers. This indicated that nicotine stimulation led to a periodic increase in SFR, which disturbed the pathogenic activity and the presence of tar prevented caries progression [23]. However, the continuous stimulation of the taste receptor diminishes SFR and minimizes the protective effect on the periodontal tissues $[18,24]$. Therefore, the active smokers in the present study displayed poor oral hygiene and mild to moderate gingival recession, irrespective of their gender and age. Moreover, pigmentation of oral mucosa, calculus deposits and active caries was common in the majority of the active smokers involved in the study. Hence, suggesting the critical importance of oral hygiene maintenance in the oral health, independent of nicotine exposure through smoking.

Gender and age play a critical role in instigating changes in saliva production and associated disorders $[25,26]$. The present study highlighted similar outcomes to the previous findings, showing higher COD scores, and lower SFR and IgA levels, in the $>35$ years age group, suggesting an evident impact of age on saliva production $[25,26]$. However, the findings were suggestive that smoking affected both genders differently; the females displayed a significant impact of smoking on the IgA levels, whereas SFR and COD scores were greatly affected in the males included in both smoker groups. The increased SFR in females, as compared to males, defines a direct relation to the difference in the hormonal status [27]. On the contrary, some studies further explained that with age the female hormonal flow reduces (post-menopausal estrogen levels), which often leads to the reduction of salivary flow in old age [28]. Thus, the impact of age and gender are interrelated.
The personal habit of tobacco chewing or smoking is a potential cause of impaired oral health and saliva production. Various studies have provided supporting evidence that, after initial stimulation, the long-term exposure eventually reduces SFR, which initiates associated oral health problems such as dry mouth and caries $[18,20]$. However, one of the limitations of the study was the difference in exposure time to tobacco smoke between the passive and active smokers. In addition, the study was single-centered with no equal distribution of age, gender and types of smokers, which might have influenced the correlation and introduced bias. Moreover, the absence of non-smokers in the present study is a limitation. Therefore, it is recommended to conduct future studies that include the tobacco smoke exposure period estimated through routine biochemical assessments and compare outcomes with non-smokers. These studies would assist healthcare professionals in promoting smoking education, to determine passive smoke risks and to plan prevention policies with a view to lowering the risk related to passive smoking.

\section{CONCLUSIONS}

The study demonstrated a significant difference in SFR, IgA levels and COD scores among the active and passive smokers. However, the outcomes indicated that the number of cigarettes had a negative impact on saliva production, salivary IgA, the oral health status, and the progression of active caries with respect to age and gender. This suggested that a long smoking history leads to the chronic condition of xerostomia, which facilitates active caries progress.

\section{ACKNOWLEDGEMENT}

The authors extend their appreciation to the Deputyship for Research and Innovation, the Ministry of Education in Saudi Arabia, for funding this research work through project No. IFKSURG-1438-075. 


\section{REFERENCES}

1. OECD, World Health Organization [Internet]. Geneva: The Organization; 2020 [cited 2020 Dec 1]. Tobacco. Available from: https://www.oecd-ilibrary.org/social-issues-migration-health/health-at-a-glance-asia-pacific-2020_2c5c93 96-en.

2. Robinson JH, Griffith DW Jr, Conner BT, Crooks EL, Dempsey-Bailey-Brewer J. Tobacco-containing smoking article. United States Patent US 7726320 B2. 2010 Jun 1.

3. Khemiss M, Khelifa MB, Saad HB. Preliminary findings on the correlation of saliva $\mathrm{pH}$, buffering capacity, flow rate and consistency in relation to waterpipe tobacco smoking. Libyan J Med. 2017;12(1), https://doi.org/10.1080/19932820.2017. 1289651.

4. Grover N, Sharma J, Sengupta S, Singh S, Singh N, Kaur H. Long-term effect of tobacco on unstimulated salivary $\mathrm{pH}$. J Oral Maxfac Path. 2016;20(1):16, https://doi.org/10.4103/ 0973-029X.180907.

5. Närhi TO. Prevalence of subjective feelings of dry mouth in the elderly. J Den Res. 1994;73(1):20-5, https://doi.org/ 10.1177/00220345940730010301.

6. Singh M, Ingle NA, Kaur N, Yadav P, Ingle E. Effect of longterm smoking on salivary flow rate and salivary $\mathrm{pH}$. J Ind Assoc Public Health Dent. 2015;13(1):11, https://doi.org/10. 4103/2319-5932.153549.

7. Golpasand-Hagh L, Zakavi F, Ansarifar S, Ghasemzadeh O, Solgi G. Association of dental caries and salivary sIgA with tobacco smoking. Aus Dent J. 2013;58(2):219-23, https://doi. org//10.1111/adj.12059.

8. Arbabi-Kalati F, Salimi S, Nabavi S, Rigi S, Miri-Moghaddam M. Effects of tobacco on salivary antioxidative and immunologic systems. Asian Pacific J Cancer Pre. 2017;18(5):1215, https://doi.org/10.22034/APJCP.2017.18.5.1215.

9. Osailan S, Pramanik R, Shirlaw P, Proctor G, Challacombe S. Clinical assessment of oral dryness: development of a scoring system related to salivary flow and mucosal wetness. Oral Surg, Oral Med, Oral Patho Oral Rad. 2012;114(5):597-603, https://doi.org/10.1016/j.oooo.2012.05.009.
10. Jager DHJ, Bots CP, Forouzanfar T, Brand HS. Clinical oral dryness score: evaluation of a new screening method for oral dryness. Odontology. 2018;106(4):439-44, https://doi. org/10.1007/s10266-018-0339-4.

11. Petrušić N, Posavac M, Sabol I, Mravak-Stipetić M. The effect of tobacco smoking on salivation. Acta Stomatol Croatica. 2015;49(4):309-15, https://doi.org/10.15644/asc49/4/6.

12. Holliday RS, Campbell J, Preshaw PM. Effect of nicotine on human gingival, periodontal ligament and oral epithelial cells. A systematic review of the literature. J Dent. 2019; 86(1):81-8, https://doi.org/10.1016/j.jdent.2019.05.030.

13. Qiu F, Liang C-L, Liu H, Zeng Y-Q, Hou S, Huang S, et al. Impacts of cigarette smoking on immune responsiveness: up and down or upside down? Oncotarget. 2017;8(1):268, https://doi.org/10.18632/oncotarget.13613.

14. Suzuki N, Nakanishi K, Yoneda M, Hirofuji T, Hanioka T. Relationship between salivary stress biomarker levels and cigarette smoking in healthy young adults: an exploratory analysis. Tob Induc Dis. 2016;14(1):20, https://doi.org/10. 1186/s12971-016-0085-8.

15. Belisario JS, Bruggeling MN, Gunn LH, Brusamento S, Car J. Interventions for recruiting smokers into cessation programmes. Cochrane Database Syst Rev. 2012;12(12): CD009187, https://doi.org/10.1002/14651858.CD009187.

16. Caponnetto P, Idrisov B, Signorelli MS, Krupitsky E, Kiriazova T, Nilforooshan R, et al. A 12-month randomised, doubleblind, controlled, multicentre trial comparing changes in Cigarette consumption after switchinG to high or low nicotine strENght E-cigaretteS In smokers with Schizophrenia spectrum disorders: Protocol for the GENESIS Trial. medRxiv. 2020, https://doi.org/10.1101/2020.10.15.20141457.

17. Vohra F, Akram Z, Bukhari IA, Sheikh SA, Riny A, Javed F. Comparison of Periodontal Inflammatory Parameters and Whole Salivary Cytokine Profile Among Saudi Patients with Different Obesity Levels. Int J Perio Rest Dent. 2018;38(6): e119-26, https://doi.org/10.11607/prd.3411.

18. Ueno M, Ohara S, Sawada N, Inoue M, Tsugane S, Kawaguchi Y. The association of active and secondhand smoking 
with oral health in adults: Japan public health center-based study. Tob Induc Dis. 2015;13(1):19-25, https://doi.org/10. 1186/s12971-015-0047-6.

19. Justino AB, Teixeira RR, Peixoto LG, Jaramillo OLB, Espindola FS. Effect of saliva collection methods and oral hygiene on salivary biomarkers. Scand J Clin Lab Inves. 2017;77(6):415-22, https://doi.org/10.1080/00365513.2017. 1334261.

20. Giuca MR, Pasini M, Tecco S, Giuca G, Marzo G. Levels of salivary immunoglobulins and periodontal evaluation in smoking patients. BMC Immunol. 2014;15(1):5-11, https:// doi.org/10.1186/1471-2172-15-5.

21. Iida $\mathrm{T}$, Ono $\mathrm{K}$, Inagaki $\mathrm{T}$, Hosokawa R, Inenaga K. Nicotinic receptor agonist-induced salivation and its cellular mechanism in parotid acini of rats. Autonomic Neurosci. 2011; 161(2):81-6, https://doi.org/10.1016/j.autneu.2011.01.003.

22. Arinola O, Akinosun O, Olaniyi J. Passive-and active-cigarette smoking: Effects on the levels of antioxidant vitamins, immunoglobulin classes and acute phase reactants. Afri J Biotech. 2011;10(32):6130-2.

23. Shah AH, ElHaddad SA. Oral hygiene behavior, smoking, and perceived oral health problems among university students.
J Int Soc Prev Com Dent. 2015;5(4):327-31, https://doi.org/ 10.4103/2231-0762.161765.

24. Hellqvist L. Smoking, snuffing and oral health with special reference to dental caries [Internet]. Gothenburg: University of Gothenburg, Karlstadt University; 2012 [cited 2020 Dec 1]. Available from: https://core.ac.uk/download/pdf/ 16333683.pdf.

25. Liu B, Dion MR, Jurasic MM, Gibson G, Jones JA. Xerostomia and salivary hypofunction in vulnerable elders: prevalence and etiology. Oral Surg, Oral Med, Oral Patho Oral Rad. 2012;114(1):52-60, https://doi.org/10.1016/j.oooo. 2011.11.014.

26. Ekström J, Khosravani N, Castagnola M, Messana I. Saliva and the control of its secretion. In: Ekberg O, editor. Dysphagia. Medical Radiology. Heidelberg: Springer; 2019.

27. Lukacs JR. Sex differences in dental caries experience: clinical evidence, complex etiology. Clin Oral Inves. 2011; 15(5):649-56, https://doi.org/10.1007/s00784-010-0445-3.

28. Mahesh D, Komali G, Jayanthi K, Dinesh D, Saikavitha T. Evaluation of salivary flow rate, $\mathrm{pH}$ and buffer in pre, post \& postmenopausal women on HRT. J Clin Diag Res. 2014;8(2): 233, https://doi.org/10.7860/JCDR/2014/8158.4067.

This work is available in Open Access model and licensed under a Creative Commons Attribution-NonCommercial 3.0 Poland License - http://creativecommons.org/ licenses/by-nc/3.0/pl/deed.en. 
Appendix 1. Characteristics of the clinical oral dryness score

1) Mirror sticks to the tongue

2) Mirror sticks to the buccal mucosa

3) Frothy saliva

4) Tongue shows a loss of papillae

5) No saliva pooling in the floor of the mouth

6) Glassy appearance of other oral mucosae, especially the palate

7) Altered/smooth gingival architecture

8) Active or recently restored (within the past 6 months) cervical caries (2 teeth)

9) Tongue is lobulated/fissured

10) Debris on the palate (excluding under dentures)

Appendix 2. Oral examination questionnaire

Q.1. Name:

Q.2. Age (in years):

Q.3. Gender:

male

female

Q.4. Educational qualification:
a) matric
b) intermediate
c) graduation
d) postgraduate

Q.5. Does anyone smoke at your home?
a) yes
b) no

Q.6. How many cigarettes do you smoke a day?
a) 5
b) 10
c) 15
d) 1 packet

Q.7. How often do you smoke?
a) after every meal
b) before going to bed
c) every morning
d) at no particular time

Q.8. Have you noticed a discernible change in saliva production? Is it reduced, exaggerated, or you cannot tell?
a) yes
b) no
c) cannot tell

Q.9. Have you noticed any significant change in taste?
a) yes
b) no

Q.10. Does your mouth feel dry at any given time; if yes, is it during the night or upon awakening?
a) yes, in the morning
b) yes, at night
c) no 
Q.11. Do you face any difficulty while swallowing any type of food?
a) yes
b) no

Q.12. Do you use the assistance of liquids to help with the swallowing of solid food?
a) yes
b) no

\section{Clinical oral dryness (COD) score}

Mirror sticks to the buccal mucosa: yes/no

Mirror sticks to the tongue: yes/no

Tongue lobulated/fissured: yes/no

Tongue shows a loss of papillae: yes/no

Frothy saliva: yes/no

No saliva pooling in the floor of the mouth: yes/no

Glassy appearance of oral mucosa, especially the palate: yes/no

Debris on the palate (excluding debris under dentures): yes/no

Altered/smooth gingival architecture: yes/no

Active or recently restored cervical caries ( $>2$ teeth): yes/no

Total score:

\begin{tabular}{ll|l}
\hline \multicolumn{1}{c}{ Oral examination } & Tooth No. \\
\hline Cervical carries & & \\
\cline { 2 - 2 } Occlusal carries & & \\
\cline { 2 - 2 } Tooth mobility & & \\
\cline { 2 - 2 } Calculus & & \\
& & \\
Bleeding on probing & & \\
\end{tabular}

Are any oral lesions present and visible? yes/no

Location of the oral lesion

$\square$ buccal
$\square$ tongue
$\square$ gingival

$\square$ lip

$\square$ palate 